\title{
The Effects of Galactosamine-Induced Hepatic Failure Upon Blood-Brain Barrier Permeability
}

\author{
Warken D. Lo, $\dagger$ Steven R. Ennis, Gary W. Goldstein, David L. McNeely and A. Lorris Betz \\ Departments of Pediatrics and Neurology, University of Michigan, Ann Arbor, Michigan 48109 and Columbus Children's \\ Hospital, Columbus, Ohio 43205
}

The role of changes in blood-brain barrier permeability in the pathogenesis of hepatic encephalopathy remains uncertain. To test the hypothesis that brain microvessel permeability is nonselectively increased in hepatic encephalopathy we measured the blood-brain barrier permeability-surface area product in rats with acute liver failure induced by intraperitoneal injection of galactosamine. The permeability-surface area products to the diffusion-limited tracers, sucrose and methylaminoisobutyric acid, were determined as a measure of blood-brain barrier permeability. Animals were examined 24,36 and 42 hr after injection, at times when they were stuporous, but not comatose. No significant elevations of the permeability-surface area products for either compound were detected in clinically affected experimental animals when compared to controls. Our results indicate there is no generalized increase in brain vascular permeability during hepatic insufficiency in precomatose animals.

The mechanism by which hepatic encephalopathy is produced remains unclear. Several investigators have reported increases in blood-brain barrier (BBB) permeability following experimental liver injury (1-3), and they propose that these changes play a role in the pathogenesis of encephalopathy. Other investigators found no generalized BBB opening (4-6). This discrepancy may be explained, in part, by the low sensitivity of the method used to measure BBB permeability. Most of these studies employed the single-pass, intracarotid injection technique. However, when used to measure brain uptake of poorly diffusible compounds, this method requires large corrections for tracer retained within the intravascular compartment (7). The integrity of the BBB can be meas-

Received January 29, 1986; accepted February 12, 1987.

† Present address: Division of Pediatric Neurology, B-409, Children's Hospital, 700 Children's Drive, Columbus, Ohio 43205.

This work was supported by grants from the National Institutes of Health (ESO2380, EYO3772) and the American Heart Association (83750).

Dr. Lo was supported by an NRSA fellowship (NSO7222).

Dr. Ennis was supported by a fellowship from The American Heart Association of Michigan.

Dr. Betz is an Established Investigator of the American Heart Association.

Address reprint requests to: A. Lorris Betz, M.D., Ph.D., University of Michigan Medical Center, Pediatric Neurology Research, R6060 Kresge Research II, Box 0570, Ann Arbor, Michigan 48109-0570. ured more accurately with a technique developed by Ohno et al. (8). The BBB permeability-surface area product (PS) is determined following an intravenous injection of radiolabeled sucrose. The sucrose content in brain can be corrected for the intravascular portion by determining brain blood volume in a separate group of animals. We used this method to test the hypothesis that there is a generalized increase in BBB permeability during galactosamine-induced liver failure.

\section{MATERIALS AND METHODS}

General Procedures. Male Sprague-Dawley rats weighing 250 to $350 \mathrm{gm}$ were given an intraperitoneal injection of $\mathrm{D}+$ galactosamine hydrochloride ( $3 \mathrm{gm}$ per $\mathrm{kg}$ ) as a $0.28 \mathrm{M}$ solution $(\mathrm{pH} 7.4)$ in water $(9,10)$. Control animals were injected with $0.28 \mathrm{M}$ glucose in water. The animals were fed standard laboratory chow and $10 \mathrm{gm} \%$ glucose was added to their water.

At 24, 36 and $42 \mathrm{hr}$ after the galactosamine injection, the animals were anesthetized with sodium pentobarbital $(50 \mathrm{mg}$ per $\mathrm{kg}, \mathrm{i}$. p.) and tracheotomized. Polyethylene catheters were inserted into all four femoral vessels. The left femoral artery catheter was connected to a blood pressure transducer to monitor blood pressure as well as to collect blood-gas samples. The right femoral artery catheter was connected to a peristaltic pump to permit continuous arterial blood withdrawal. One venous catheter was used for intravenous injection of drugs while the other intravenous catheter was used for injection of radioactive tracers.

The animals were paralyzed with gallamine, and ventilated using a volume ventilator set to maintain the arterial $\mathrm{pCO}_{2}$ between 35 and $45 \mathrm{~mm} \mathrm{Hg}$. Temperature was monitored by a rectal probe and maintained at $36.5^{\circ}$ to $37.5^{\circ} \mathrm{C}$ with an incandescent lamp.

Serum enzyme and bilirubin assays were performed in the clinical laboratory of the Columbus Children's Hospital using a Kodak Ektachem-700 ${ }^{n}$ analyzer.

Injection of Isotopes. For measurement of both BBB permeability (PS) and cerebral blood volume, the animals were allowed to reach a steady state 15 to 30 min following cannulation. Radioactive tracers were injected intravenously. During PS determinations, arterial blood was withdrawn from the right femoral artery at a known rate. When a predetermined amount of time had elapsed, a terminal arterial blood sample was collected from the left femoral artery, the animal was decapitated and the continuous arterial withdrawal was stopped. The forebrain was separated into right and left halves, then divided into cerebral hemispheres and basal ganglia. The brainstem was separated from the cerebellum. The brain regions were placed in preweighed scintillation vials containing Protosol and 
reweighed. Blood from the continuous arterial withdrawal was expelled into a preweighed vial, weighed and $50 \mu \mathrm{l}$ aliquots were placed in scintillation vials containing a 2:1 (volume/volume) mixture of ethanol:Protosol. The terminal arterial blood hematocrit was measured, and $50-\mu 1$ aliquots of the blood were also dissolved in ethanol:Protosol. Brain and blood samples were heated at $65^{\circ} \mathrm{C}$ until they were digested. The blood samples were bleached with $50 \mu \mathrm{l} 30 \%$ hydrogen peroxide. Toluenebased scintillation cocktail was added to all samples, and the amount of radioisotope present was assayed by liquid scintillation using single or double channels as appropriate.

Blood Volume Measurement. Regional brain plasma volume and red blood cell volume were determined using a variation of a method previously described $(11,12)$. Homologous rat red blood cells were incubated with $300 \mu \mathrm{Ci}{ }^{51} \mathrm{Cr}$ per $1.2 \mathrm{ml}$ packed cells for $30 \mathrm{~min}$ at $37^{\circ} \mathrm{C}$. The labeled red cells were then washed three times with iced phosphate-buffered saline (PBS) containing $10 \mathrm{mM}$ glucose and kept on ice. Just prior to use, a 200- $\mu$ l aliquot of cells was washed with PBS and suspended with $100 \mu \mathrm{l} 1 \%$ bovine serum albumin (BSA) in PBS containing $10 \mu \mathrm{Ci}^{125} \mathrm{I}$-labeled BSA $(1.39 \mu \mathrm{Ci}$ per mg BSA). The suspension was injected via the left femoral venous line. The labeled cells and plasma were allowed to circulate for $2 \mathrm{~min}$, then a terminal arterial blood sample was rapidly withdrawn and the animal was decapitated. The samples were subsequently handled as described in the general procedures. The radioactive content was determined in a two-channel liquid scintillation counter that was calibrated for simultaneous counting of the Auger and conversion electrons emitted by ${ }^{51} \mathrm{Cr}$ and ${ }^{125} \mathrm{I}$ (13). Typical counting efficiencies were 20 and $20 \%$ for channel $\mathrm{A}$, and 1 and $33 \%$ for channel $\mathrm{B}$, for ${ }^{51} \mathrm{Cr}$ and ${ }^{125} \mathrm{I}$, respectively.

PS. A $10 \mu \mathrm{Ci}$ aliquot of $\left[{ }^{14} \mathrm{C}\right]$ sucrose $(560 \mu \mathrm{Ci}$ per mmole) or $\left[{ }^{14} \mathrm{C}\right]$ methyl-aminoisobutyric acid [(MAIB), 40 to $60 \mathrm{mCi}$ per mmole] in PBS was injected intravenously. Arterial blood was continuously withdrawn for $10 \mathrm{~min}$, then a terminal blood sample was obtained and the animal was killed. Tissues and blood were handled as in general procedures.

Calculations. Assuming that the PS for sucrose or MAIB is much less than the regional cerebral blood flow, and that the early brain concentration of either isotope is negligibly small (7), PS may be determined by the following relationship:

$$
P S=\frac{C_{b}}{\int_{n}^{t} C_{n} d t}
$$

where $\mathrm{C}_{\mathrm{b}}=$ the amount of isotope in the brain region and $\mathrm{C}_{\mathrm{a}}=$ the amount of isotope in the arterial blood at a given time, $t$. The integral of $C_{n} d t$ between the time of isotope injection and termination of the experiment can be estimated by using a continuous arterial withdrawal at a known rate using the following equation:

$$
\int_{11}^{t} C_{\mathrm{a}} \mathrm{dt}=\frac{\mathrm{C}_{\mathrm{o}}}{\mathrm{F}_{\mathrm{o}}}
$$

where $\mathrm{C}_{\mathrm{C}}=$ total amount of isotope in the arterial blood sample and $F_{0}=$ the withdrawal rate of the pump (14). Knowing the tissue plasma volume (PV), the following relationship can be made:

$$
\mathrm{PS}=\left[\frac{\text { brain dpm }}{\text { brain weight }}-\left(\mathrm{C}_{t}{ }^{*} \mathrm{PV}\right)\right] * \mathrm{~F}_{0}{ }^{*}\left(1-\mathrm{Hct}_{\mathrm{a}}\right) / \mathrm{C}_{0}
$$

where $C_{t}=$ the terminal arterial concentration of isotope and Hct $_{\mathrm{s}}=$ the arterial hematocrit. PV is calculated from the following equation using $\mathrm{Hct}_{\mathrm{a}}$ and values for regional blood volume (BV) and the ratio (R) of tissue to peripheral hematocrits determined in a separate group of animals:

$$
\mathrm{PV}=\mathrm{BV}^{*}\left(1-\mathrm{Hct}_{\mathbf{a}}{ }^{*} \mathrm{R}\right) \text {. }
$$

Thus, the plasma volume term takes into account any variability in peripheral hematocrits between groups of animals.

Materials. Animals were purchased from Harlan Sprague-Dawley, Inc. (Haslett, Mich.). Chemicals were obtained from Sigma Chemical Co. (St. Louis, Mo.) and were reagent grade. Protosol and $\alpha-\left[1{ }^{14} \mathrm{C}\right] \mathrm{MAIB}(48.4 \mathrm{mCi}$ per mmole) were purchased from DuPont-NEN (Boston, Mass.). $\left({ }^{14} \mathrm{C}\right]$ Sucrose $\left(10.0 \mathrm{mCi}\right.$ per mmole) and ${ }^{125} \mathrm{I}$-BSA $(0.8 \mathrm{mCi}$ per mg) were purchased from ICN (Irvine, Calif.).

Statistical Analysis. Results were assumed to be random samples that were mutually independent under the experimental conditions. Because of small sample sizes, a normal distribution was not assumed, and nonparametric statistical tests were selected. For the data in Tables 1 to 4 , results from three experimental animal groups were compared simultaneously with controls by the Kruskal-Wallis test using $\alpha=0.01$. For comparisons of the single MAIB uptake group to controls, the

\begin{tabular}{|c|c|c|c|c|}
\hline & Control & $24 \mathrm{hr}$ & $36 \mathrm{hr}$ & $42 \mathrm{hr}$ \\
\hline \multicolumn{5}{|c|}{$\begin{array}{l}\text { Regional blood volume determination } \\
\text { animals }\end{array}$} \\
\hline Weight (gm) & $314 \pm 37$ & $342 \pm 23$ & $260 \pm 29$ & $240 \pm 19$ \\
\hline Temperature $\left({ }^{\circ} \mathrm{C}\right)$ & $37.6 \pm 0.6$ & $37.5 \pm 0.6$ & $37.2 \pm 0.3$ & $37.4 \pm 0.9$ \\
\hline $\mathrm{pH}$ & $7.39 \pm 0.04$ & $7.37 \pm 0.04$ & $7.28 \pm 0.09$ & $7.33 \pm 0.13$ \\
\hline $\mathrm{pCO}_{2}(\mathrm{~mm} \mathrm{Hg})$ & $39 \pm 3$ & $39 \pm 4$ & $40 \pm 4$ & $39 \pm 2$ \\
\hline \multicolumn{5}{|l|}{ PS determination animals } \\
\hline Weight (gm) & $240 \pm 48$ & $212 \pm 31$ & $232 \pm 24$ & $182 \pm 49$ \\
\hline Blood pressure $(\mathrm{mm} \mathrm{Hg}$ ) & $102 \pm 16$ & $66 \pm 10$ & $80 \pm 10$ & $85 \pm 12$ \\
\hline Temperature $\left({ }^{\circ} \mathrm{C}\right)$ & $37.6 \pm 0.9$ & $3.68 \pm 0.6$ & $37.4 \pm 0.5$ & $37.8 \pm 0.6$ \\
\hline $\mathrm{pH}$ & $7.35 \pm 0.05$ & $7.36 \pm 0.07$ & $7.35 \pm 0.05$ & $7.30 \pm 0.1$ \\
\hline $\mathrm{pCO}_{2}(\mathrm{~mm} \mathrm{Hg})$ & $41 \pm 5$ & $40 \pm 5$ & $38 \pm 3$ & $39 \pm 2$ \\
\hline
\end{tabular}
Mann-Whitney rank sum test was employed using the same $\alpha$ $=0.01(15,16)$

Table 1. Physiological parameters

Each value is the mean \pm S.D. of determinations from five animals. 
TABLE 2. Blood chemistry values in glactosamine-injected rats

\begin{tabular}{lcccc}
\hline & Control & $\mathbf{2 4}$ hr & 36 hr & 42 hr \\
\hline AST (IU/liter) & $120 \pm 37$ & $\mathbf{9 , 4 9 9} \pm 9,383$ & $15,234 \pm 6,545$ & $7,753 \pm 3,973$ \\
ALT (IU/liter) & $53 \pm 6$ & $4,395 \pm 5,264$ & $13,454 \pm 6,559$ & $5,687 \pm 3,128$ \\
Total bilirubin (mg/dl) & $0.3 \pm 0.1$ & $1.1 \pm 0.8$ & $3.3 \pm 1.6$ & $2.4 \pm 0.6$ \\
Direct bilirubin (mg/dl) & $0.1 \pm 0.1$ & $0.8 \pm 0.6$ & $1.5 \pm 1.0$ & $2.3 \pm 0.6$ \\
\hline
\end{tabular}

Each value is the mean \pm S.D. of determinations from 5 to 7 animals.

TABLE 3. Regional volume and hematocrit determinations

\begin{tabular}{|c|c|c|c|c|}
\hline & Control & $24 \mathrm{hr}$ & $36 \mathrm{hr}$ & $42 \mathrm{hr}$ \\
\hline \multicolumn{5}{|l|}{$\begin{array}{c}\text { Tissue plasma } \\
\text { volume }^{a}\end{array}$} \\
\hline Cortex & $5.1 \pm 0.6$ & $5.5 \pm 0.6$ & $5.6 \pm 0.2$ & $5.3 \pm 1.1$ \\
\hline Basal ganglia & $6.6 \pm 1.4$ & $6.8 \pm 0.8$ & $7.0 \pm 0.8$ & $7.0 \pm 0.6$ \\
\hline Cerebellum & $7.7 \pm 1.0$ & $8.4 \pm 0.9$ & $8.9 \pm 1.0$ & $8.5 \pm 0.5$ \\
\hline Brainstem & $6.7 \pm 0.8$ & $7.1 \pm 0.9$ & $7.4 \pm 0.4$ & $7.6 \pm 0.4$ \\
\hline \multicolumn{5}{|l|}{$\begin{array}{c}\text { Tissue red cell } \\
\text { volume }^{a}\end{array}$} \\
\hline Cortex & $1.8 \pm 0.2$ & $2.4 \pm 0.2$ & $2.1 \pm 0.2$ & $2.1 \pm 0.7$ \\
\hline Basal ganglia & $3.0 \pm 0.5$ & $4.3 \pm 0.9$ & $3.0 \pm 0.2$ & $4.1 \pm 1.5$ \\
\hline Cerebellum & $3.0 \pm 0.3$ & $3.8 \pm 0.4$ & $3.9 \pm 1.0$ & $3.6 \pm 0.8$ \\
\hline Brainstem & $2.3 \pm 0.3$ & $2.9 \pm 0.2$ & $2.9 \pm 0.6$ & $3.1 \pm 0.6$ \\
\hline \multicolumn{5}{|l|}{$\begin{array}{r}\text { Tissue blood } \\
\text { volume }^{a}\end{array}$} \\
\hline Cortex & $7.0 \pm 0.8$ & $7.8 \pm 0.8$ & $7.7 \pm 0.2$ & $7.67 \pm 1.7$ \\
\hline Basal ganglia & $9.6 \pm 1.3$ & $11.1 \pm 1.6$ & $10.1 \pm 0.9$ & $11.1 \pm 1.6$ \\
\hline Cerebellum & $10.7 \pm 1.1$ & $12.2 \pm 1.2$ & $12.9 \pm 1.9$ & $12.1 \pm 0.9$ \\
\hline Brainstem & $9.0 \pm 1.0$ & $10.0 \pm 1.0$ & $10.3 \pm 0.9$ & $10.7 \pm 0.6$ \\
\hline \multicolumn{5}{|l|}{ Tissue hematocrit } \\
\hline Cortex & $0.26 \pm 0.01$ & $0.30 \pm 0.02$ & $0.27 \pm 0.02$ & $0.28 \pm 0.05$ \\
\hline Basal ganglia & $0.32 \pm 0.07$ & $0.38 \pm 0.03$ & $0.30 \pm 0.02$ & $0.36 \pm 0.09$ \\
\hline Cerebellum & $0.28 \pm 0.03$ & $0.31 \pm 0.02$ & $0.30 \pm 0.03$ & $0.30 \pm 0.05$ \\
\hline Brainstem & $0.26 \pm 0.02$ & $0.29 \pm 0.02$ & $0.28 \pm 0.04$ & $0.29 \pm 0.05$ \\
\hline
\end{tabular}

Each value is the mean \pm S.D. of determinations from five animals. ${ }^{a}$ In $\mu \mathrm{l} / \mathrm{gm}$ tissue weight.

TABLE 4. Sucrose PS ${ }^{a}$ determination

\begin{tabular}{lccrr}
\hline & Control & \multicolumn{1}{c}{$\mathbf{2 4} \mathbf{~ h r}$} & \multicolumn{1}{c}{$\mathbf{3 6} \mathbf{~ h r}$} & \multicolumn{1}{c}{$\mathbf{4 2 ~} \mathbf{~ h r}$} \\
\hline Cortex & $8.2 \pm 1.5$ & $10.8 \pm 3.2$ & $7.4 \pm 1.2$ & $8.5 \pm 1.9$ \\
Basal ganglia & $10.6 \pm 1.7$ & $11.3 \pm 0.4$ & $10.9 \pm 0.6$ & $10.3 \pm 2.6$ \\
Cerebellum & $11.1 \pm 0.7$ & $10.2 \pm 0.8$ & $9.2 \pm 1.6$ & $9.7 \pm 2.1$ \\
Brainstem & $9.6 \pm 2.4$ & $10.6 \pm 2.2$ & $8.8 \pm 1.9$ & $10.4 \pm 2.3$ \\
\hline
\end{tabular}

Each value is the mean \pm S.D. of determinations for five animals. ${ }^{a}$ In $\mathrm{ml} / \mathrm{gm} / \mathrm{min} \times 10^{4}$.

\section{RESULTS}

At $24 \mathrm{hr}$ after administration of galactosamine, the urine and plasma of the experimental rats were icteric, but the animals showed no behavioral difference from control animals. By $36 \mathrm{hr}$, the animals were listless, and they startled easily. At $42 \mathrm{hr}$, the rats were awake, but poorly responsive to the environment. By this time, two animals had died after a period of irritability followed by stimulus-induced tonic seizures. When physiological parameters were compared, animals at 36 to $42 \mathrm{hr}$ were more acidotic and hypotensive than the 24-hr experimental rats (Table 1 ).

We measured serum aminotransferases, and total and direct bilirubin to characterize the extent of liver damage. In animals injected with glucose, values for AST, ALT, total bilirubin and direct bilirubin remained constant for at least $48 \mathrm{hr}$ after injection (data not shown). In animals injected with galactosamine, serum aminotransferases steadily rose to a maximum at $36 \mathrm{hr}$ after galactosamine injection and declined by $42 \mathrm{hr}$, although the aminotransferase levels remained greater than control values (Table 2 ). Serum direct bilirubin steadily increased above control values after galactosamine injection at all time points measured. All values at 24,36 and $42 \mathrm{hr}$ were significantly different from controls $(\mathrm{p}<0.01)$. The pronounced rise in serum aminotransferases and the progressing hyperbilirubinemia point to the severity of galactosamineinduced hepatic injury.

No significant increases from control values were noted in tissue plasma volumes, red cell volumes, blood volumes and tissue hematocrits in the cortex, basal ganglia, cerebellum and brainstem of galactosamine-treated animals at 24,36 or $42 \mathrm{hr}$ (Table 3). Brain blood volumes, expressed as microliters per gram of brain weight, did not vary with body weight in the animals examined (comparison not shown). The only multiple sample comparisons that approached significance were an increase in tissue red cell volumes for the cortex $(p=0.037)$ and the brainstem $(p=0.049)$ when results at different time points were compared to controls. The differences were most notable between controls and 24 -hr animals than at other times.

PS was calculated for sucrose using the blood volumes shown in Table 2. At all times following galactosamine injection, PS for affected animals did not differ significantly from controls (Table 4). This was true at $24 \mathrm{hr}$ when animals were behaviorly unaffected as well as at 36 and $42 \mathrm{hr}$ when their behavior was distinctly abnormal.

Other investigators have reported significant increases in the regional PS product for aminoisobutyric acid in galactosamine-treated rabbits (2). In order to determine whether this observation was the result of a specific change in brain uptake of this type of amino acid analog, we determined the PS product for MAIB in rats $24 \mathrm{hr}$ after galactosamine administration. We found no increase in PS for MAIB compared to controls. In fact, the MAIB-PS in all regions was lower than control (Table 5 ). While MAIB enters the brain very poorly, it is possible that a portion of its brain uptake is mediated by an amino acid transport system. Reduced brain uptake of MAIB in galactosamine-treated rats might, therefore, be explained by competition for transport from the elevated plasma concentrations of other neutral amino acids during hepatic failure (17). 
TABle 5. MAIB PS Product ${ }^{\circ}$

\begin{tabular}{lrll}
\hline & Control & $\mathbf{2 4} \mathbf{~ h r}$ & p value $^{b}$ \\
\hline Cortex & $8.1 \pm 1.1$ & $6.5 \pm 0.9$ & 0.012 \\
Basal ganglia & $6.7 \pm 2.7$ & $3.1 \pm 1.3$ & 0.07 \\
Cerebellum & $10.9 \pm 1.7$ & $7.2 \pm 1.3$ & 0.018 \\
Brainstem & $11.1 \pm 2.7$ & $7.2 \pm 2.1$ & 0.012 \\
\hline
\end{tabular}

Each value is the mean \pm S.D. for six control and three experimental animals.

${ }^{a}$ In $\mathrm{ml} / \mathrm{gm} / \mathrm{min} \times 10^{4}$

${ }^{\circ}$ One-tailed test.

\section{DISCUSSION}

During the course of galactosamine-induced acute hepatic failure, we found no change in BBB permeability to sucrose despite the increasing duration of hepatic injury and progressive alterations in behavior. During the times studied, all animals showed evidence of severe liver damage. By $36 \mathrm{hr}$, they were less active and by 42 hr they were either lethargic or hyperirritable, but not comatose.

Our results are in agreement with other studies which found no change in BBB permeability following liver injury. In one study, rats with chronic portacaval shunts were given ammonium acetate to acutely induce encephalopathy (4). There was no difference in the brain uptake of sucrose compared with controls. A second study used a similar method without ammonia loading; no change in the BBB permeability to inulin was found (5). A third study found no change in brain uptake of ${ }^{22} \mathrm{Na}$ and ${ }^{51} \mathrm{Cr}$ EDTA in rats examined 3 weeks after the creation of a portacaval shunt (6). These three studies used the intracarotid bolus injection method to measure the brain uptake index, although this technique is relatively insensitive to changes in BBB permeability for poorly diffusible compounds. In a fourth study, Mans et al. (18) used the technique of quantitative autoradiography, which is more sensitive than the brain uptake index technique to determine BBB permeability to sucrose. They found no change in PS in rats examined 7 to 8 weeks after portacaval shunting. Mans et al. did not examine BBB changes during acute hepatic encephalopathy.

Our findings conflict with the observations of Zaki et al. (1) who employed the brain uptake index technique in galactosamine-induced hepatic failure and hepatic devascularization. They detected a 3-to 4-fold increase in the uptake of inulin and a 3-fold increase in the uptake of sucrose and L-glucose. The animals were examined in deep coma and were, therefore, more severely affected than the animals in the present study. It is possible, as those authors point out, that the detected changes in $\mathrm{BBB}$ permeability reflected the moribund state of the animals.

Also, in contrast to our findings are the results of Horowitz et al. (2) who detected localized increases in BBB permeability in a rabbit model of galactosamineinduced hepatic failure. Using autoradiographic techniques to identify regional changes in isotope concentrations, the investigators examined the equilibrium transfer constant for ${ }^{14} \mathrm{C}$-labeled aminoisobutyric acid. At a time before the animals became encephalopathic, in- (reases in the aminoisobutyric acid transfer constant occurred in the medial geniculate body, superior colliculus, central grey substance, area retrosplenius and lateral thalamic nucleus. Less pronounced changes were noted in the limbic regions, basal ganglia and temporal cortex. Other cortical regions and white matter tracts were unaffected.

One possible explanation for the differences between our results and those of Horowitz et al. (2) is that the permeability change they observed is specific for aminoisobutyric acid and not sucrose. Aminoisobutyric acid normally has a low BBB permeability because the carrier for which this amino acid analog has the highest affinity is found on the antiluminal but not the luminal membrane of the brain capillary endothelial cell (19). Redistribution of this transport protein to the luminal membrane could result in a selective increase in BBB permeability to aminoisobutyric acid with no change in permeability to sucrose (20). The fact that BBB permeability to MAIB, a similar amino acid analog, did not increase in our model, makes this redistribution of carriers unlikely. Alternatively, it is possible that the highly localized increases in BBB permeability detected by the autoradiographic method of Horowitz et al. could not be resolved by our method, which required analysis of larger pieces of brain containing many brain structures.

We conclude that galactosamine-induced hepatic injury does not produce a generalized breakdown of the BBB in premoribund animals. However, it remains possible that localized changes in BBB permeability may occur in specific brain regions. Future research should attempt to confirm that $\mathrm{BBB}$ permeability does increase in brain structures, like the medial geniculate body and the lateral thalamus, since an analysis of the causes and consequences of BBB breakdown in those regions could provide important insights into the pathogenesis of hepatic encephalopathy.

\section{REFERENCES}

1. Zaki AEO, Ede RJ, Davis M, et al. Experimental studies of bloodbrain barrier permeability in acute hepatic failure. Hepatology 1984; 4:359-363.

2. Horowitz ME, Schafer DF, Molnar P, et al. Increased blood-brain transfer in a rabbit model of acute liver failure. Gastroenterology $1983 ; 84: 1003-1011$.

3. Livingstone AS, Potvin M, Goresky CA, et al. Changes in the blood-brain barrier in hepatic coma after hepatectomy in the rat. Gastroenterology 1977; 73:697-704.

4. Mans AM, Biebuyck JF, Hawkins RA. Ammonia selectively stimulates neutral amino acid transport across blood-brain barrier. Am J Physiol 1983; 245:C74-C77.

5. James JH, Escourrou J, Fischer JE. Blood-brain neutral amino acid transport activity is increased after portacaval anastomosis. Science 1978; 200:1395-1397.

6. Sarna GS, Bradbury MWB, Cavanagh J. Permeability of the bloodbrain barrier after portacaval anastomosis in the rat. Brain Res 1977; 138:550-555.

7. Fenstermacher JD, Blasberg RG, Patlak CS. Methods for quantifying the transport of drugs across brain barrier systems. Pharmacol Ther 1981; 14:217-248.

8. Ohno K, Pettigrew KD, Rapoport SI. Lower limits of cerebrovascular permeability to non-electrolytes in the conscious rat. Am J Physiol 1978; 235:H299-H307.

9. Decker K, Keppler D. Galactosamine induced liver injury. In: Popper H, Schaffner F, eds. Progress in liver diseases, Vol 4. New 
York: Grune and Stratton, 1972: 183-199.

10. Chirito E, Lister C, Chang TMS. Biochemical, hematological, and histological changes in a fulminant hepatic failure rat model for artificial liver assessment. Artif Organs 1979; 3:42-46.

11. Cremer JE, Seville MP. Regional brain blood flow, blood volume, and hematocrit values in the adult rat. J Cereb Blood Flow Metab 1983; 3:254-256.

12. Levin VA, Ausman JI. Relationship of peripheral venous hematocrit to brain hematocrit. J Appl Physiol 1969; 26:433-437.

13. Horrocks DL. Measurement of ${ }^{125}$ I by liquid scintillation methods. Nucl Instr Meth 1976; 133:293-301

14. Preston E, Allen M, Haas N. A modified method for measurement of radiotracer permeation across the rat blood-brain barrier: the problem of correcting brain uptake for intravascular tracer. J Neurosci Meth 1983; 9:45-55.
15. Conover WJ. Practical non-parametric statistics, ed. 2. New York: John Wiley, 1980

16. Wallenstein S, Zucker CL, Heiss JL. Some statistical methods useful in circulation research. Circ Res 1980; 47:1-9.

17. Record CO, Buxton B, Chase RA, et al. Plasma and brain amino acids in fulminant hepatic failure and their relationship to hepatic encephalopathy. Eur J Clin Invest 1976; 6:387-394.

18. Mans AM, Biebuyck JF, Shelly $K$, et al. Regional blood-brain barrier permeability to amino acids after portacaval anastomosis. J Neurochem 1982; 38:705-717.

19. Betz AL, Goldstein GW. Polarity of the blood-brain barrier: neutral amino acid transport into isolated brain capillaries. Science 1978; 202:225-227.

20. Goldstein GW. The role of brain capillaries in the pathogenesis of hepatic encephalopathy. Hepatology 1984; 4:565-567. 